\title{
Variables Associated with Cirrhosis Diagnosis in Patients with Chronic Hepatitis C: A Case-Control Study
}

\author{
Gilmar Amorim de Sousa', Iris do Céu Clara Costa², Dyego Leandro Bezerra de Souza², \\ Fabia Barbosa de Andrade ${ }^{2}$, Lívia Medeiros Soares Celani' ${ }^{3}$, Ranna Santos Pessoa ${ }^{4}$, \\ Marlon César de Souza Filho4, Daniel Fernandes Mello de Oliveira4, \\ Luana Lopes de Medeiros", Lucila Samara Dantas de Oliveira4, Maria Flávia Monteiro4 \\ ${ }^{1}$ The Integrated Department of Medicine, Federal University of Rio Grande do Norte, UFRN, Natal, Brazil \\ ${ }^{2}$ The Post-Graduate Program in Collective Health of UFRN, Natal, Brazil \\ ${ }^{3}$ Gastroenterology Program of the University Hospital Onofre Lopes/UFRN, Natal, Brazil \\ ${ }^{4}$ The Medical School of UFRN, Natal, Brazil \\ Email: gilamorimdesousa@gmail.com, irisdoceu.ufrn@gmail.com,dysouz@yahoo.com.br, \\ fabiabarbosabr@yahoo.com.br, medeiroslivinha@gmail.com,rannaspessoa@gmail.com, \\ marlonsouzafilho@gmail.com, danielfernandesmo@gmail.com, luanalopesmedeiros@gmail.com, \\ lucilasamara@yahoo.com.br,mari flaviaa@hotmail.com
}

Received 8 June 2015; accepted 6 December 2015; published 9 December 2015

Copyright (C) 2015 by authors and Scientific Research Publishing Inc.

This work is licensed under the Creative Commons Attribution International License (CC BY). http://creativecommons.org/licenses/by/4.0/

\section{(c) (i) Open Access}

\section{Abstract}

The diagnosis of liver cirrhosis in patients with chronic hepatitis $\mathrm{C}$ has not always been easy, since the gold standard method is the liver biopsy, which is an invasive procedure with interobserver accuracy problems and there have been reports of complications including records of deaths due to hemoperitoneum. Cirrhosis changes the prognosis of the subject with hepatitis $C$ and requires a different clinical management. This study aimed to identify clinical and laboratory variables associated with the diagnosis of cirrhosis in the ultrasonography of patients infected with hepatitis $\mathrm{C}$. In a case-control study, we evaluated 70 cirrhotic patients with chronic hepatitis $C$ compared to a control group of 70 non-cirrhotic people with positive HCV. The results showed, through logistic regression analysis, that the variables blood donor and professional athlete, adjusted for alcohol consumption, showed $0 R \quad 0.24$ and 0.18 , with $p$ values of 0.044 and 0.035 , respectively. We conclude that the diagnosis of cirrhosis in patients with chronic hepatitis $\mathrm{C}$ remains challenging, but the patients with the condition of blood donor or professional athlete prove to be less likely to cirrhosis in ultrasonography in the initial consultation.

\section{Keywords}

Cirrhosis, Biomakers, Fibrosis, Hepatitis C Virus, Clinical Diagnosis, Biopsy, Non-Invasive, Methods, 


\section{Scores, Ultrasonography}

\section{Introduction}

Chronic hepatitis $\mathrm{C}(\mathrm{CHC})$ is the leading cause of advanced chronic liver disease in final stage of hepatocellular carcinoma (HCC), and of death related to liver disease in the Western world. It generally progresses slow and progressively, characterized by persistent inflammation and cirrhosis in approximately $10 \%$ to $20 \%$ of patients in the period of time from 20 to 30 years of infection. However, these evolutionary rates of progression to cirrhosis may vary widely depending on a number of factors from the etiologic agent, the host, and behavioral factors. Among these factors, it is mentioned that the age at which the patient has contracted the infection, alcohol consumption, obesity, insulin resistance, type 2 diabetes, the co-infections by hepatitis B-virus (HBV) and HIV, immunosuppressive therapy and genetic factors act in a multifactorial manner in the development and progression of fibrosis [1].

It is not uncommon that patients with chronic hepatitis $\mathrm{C}$ remain undiagnosed until the time that they develop complications from cirrhosis, since the natural history of the disease remains elusive [1] [2].

When cirrhosis is established, the evolution of the disease becomes unpredictable: it may remain indolent for many years or evolve aggressively, culminating with the development of HCC, hepatic decompensation and death [3] [4]. Once cirrhotic, the individual has the annual risk of $1 \%$ to $5 \%$ to develop HCC and of $3 \%$ to $6 \%$ develop decompensation. The evolutive monitoring of those presenting decompensation shows that the annual risk of death is estimated at $15 \%$ to $20 \%$.

Various studies and meta-analyzes have shown that eradication of HCV with antiviral therapy reduces the risk of HCC in patients with chronic hepatitis C, regardless of the degree of fibrosis [5] [6]. However, morbidity and mortality rates have increased exponentially when cirrhosis develops. A large study of 838 German patients showed that the mortality rate in patients under 50 years old with chronic hepatitis $\mathrm{C}$ was 3.1 , whereas in cirrhotic patients it was 26.2 for the same age [3].

D’amico et al. (2006) [4] in a systematic review of 118 studies with 23,797 patients showed an increased risk of death with the development of successive decompensations-varices, ascites, and variceal bleeding. Overall, survival rate was only 64\%, with a median follow up of 31 months.

On the other hand, it is known that the progression rate of fibrosis to cirrhosis can be variable. A study of 2235 patients with non-treated chronic hepatitis C showed a median time of 30 years for the development of cirrhosis. However, the progression rate was shorter in alcohol users, in elderly, males and patients with high inflammatory activity rates diagnosed in biopsy [7]. Thus, it is of great importance that the diagnosis of cirrhosis is done accurately and as quickly as possible, since it implies a need for effective monitoring and appropriate management of complications of liver disease.

Liver biopsy is the gold standard for fibrosis staging and diagnosis of cirrhosis. It is an invasive procedure in which a sample of liver tissue is obtained through local puncture by a needle, under anesthesia. There are several fibrosis staging scoring systems, however, the two most commonly used are METAVIR and Ishak. The METAVIR evaluates the fibrosis in 5 rating scale points: F0 has no fibrosis and F4 is equal to cirrhosis. Above F2 is considered significant degree on fibrosis and F3 - advanced fibrosis. The Ishak scoring system uses 7 points on the scale: F0 does not indicate fibrosis; F5 - incomplete cirrhosis; F6 — definite cirrhosis.

Many factors, however, may influence the accuracy of the stage of fibrosis on liver biopsy. We can mention, as an example, the size of the biopsy fragment obtained, considering that the accuracy would be correlated to the size of the biopsy specimen length. Another important aspect would be the interobserver variability, in addition to the difficulties inherent to the procedure, which as being invasive, though low risk, may not be available in all services, especially primary and secondary care [8] [9].

Liver biopsy complications have been reported in the literature in a large retrospective study and the mortality rate was estimated in about 9 per 100,000 procedures (around 0.01\%). Deaths were attributed to hemoperitoneum and occurred exclusively in patients with cirrhosis or hepatocellular carcinoma. The complication rate in this study was $0.3 \%$. Another retrospective study of 1000 biopsies showed a $5.9 \%$ complication rate with $5.3 \%$ of hospitalizations related to local pain or hypotension [10] [11].

Therefore, due to the limitations of the liver biopsy, a number of non-invasive techniques have been investi- 
gated for evaluation of fibrosis and cirrhosis diagnosis [12] [13]. A previous study has suggested that individual-based parameters such as age, albumin and stage of the disease have a direct influence on prognosis and consequently in the response to treatment.

Noninvasive markers of cirrhosis can be radiological or based on parameters collected in serum. Radiological techniques based on ultrasound, magnetic resonance imaging and elastography have been used to evaluate hepatic fibrosis. Biomarkers of cirrhosis have also been developed and classified into indirect and direct. Indirect biomarkers reflect liver function which may decline with development of cirrhosis. Direct biomarkers may reflect the renewal of extracellular matrix and include molecules involved in fibrogenesis process [14].

The high number of chronically infected patients, the prevalence of the disease and the absence of vaccination indicate that the treatment is the way of attempting to control the disease, whereas the majority of patients with persistent infection are asymptomatic. For this reason, this disease is known as the silent epidemic [1].

In order to identify clinical and laboratory variables associated with the diagnosis of cirrhosis in patients infected with the hepatitis $C$ virus, we evaluated in a case-control study 70 patients with chronic hepatitis $C$ diagnosed with cirrhosis through the ultrasonography (USG) and we performed paired comparison with the control group, 70 non-cirrhotic positive HCV people.

\section{Methods}

\subsection{Ethical Aspects}

The study was submitted to the Ethics Research Committee of the University Hospital Onofre Lopes (HUOL) of the Federal University of Rio Grande do Norte (UFRN) in the city of Natal, Rio Grande do Norte, Brazil, and was approved under the opinion number 448243/2013.

\subsection{Study Design}

It is a case-control study, identified through review of all medical records of patients treated at Núcleo de Estudos do Fígado (Liver Studies Center-NEF in Portuguese), which is a reference service in the care of patients with liver disease of the HUOL of the aforementioned University (UFRN ) from May 1995 to December 2013. The HUOL is a hospital of medium and high complexity, with 240 active beds and 7247 admissions per year.

The NEF (reference service Liver disease HUOL) began its activities in May 1995, providing outpatient care and hospitalization to patients with liver disease. It receives patients from all hospitals and clinics of the public network of Natal, the capital of Rio Grande do Norte state, as well as all other cities in the state. It has an agreement with state blood banks and receives donors with positive serology for diagnosis. Patients are welcomed by nursing professionals and attended by specialist doctors, following in the anamnesis the script of a standard questionnaire, in which are included demographic, epidemiological, clinical and laboratory variables. Patients diagnosed with chronic liver disease are advised to return with varying intervals, depending on their clinical situation and with maximum interval of six months. For evaluation purposes in clinical research, patients who failed to return to that service within 12 months are considered as follow-up dropout.

\subsection{Sample Selection}

The sample was selected in retrospective case-control study of patients with chronic hepatitis C treated at NEF of the University Hospital Onofre Lopes of UFRN. A total of 10,304 medical records were examined in a retrospective study, of which 512 showed positive HCV RNA test. We selected 70 patients with confirmed diagnosis of hepatitis $C$ and cirrhosis through ultrasound, which was the case group, compared with 70 patients with confirmed diagnosis of hepatitis $\mathrm{C}$ and who were not diagnosed with cirrhosis through ultrasound, which was the control group. Groups were matched by age and sex variables. The dependent variable was the ultrasound diagnosis of cirrhosis. As independent variables, we collected: sociodemographic variables-age, gender, marital status, profession, color and origin; variables associated with HCV infection—sexual promiscuity, intravenous drug use, whether the person is a health care professional or has profession related to risk, such as: manicure, policeman, fireman, butcher, hairdresser and barber, whether the person is or had been an athlete, or haemophiliac or performs hemodialysis, in addition to variables related to disease progression — genotype, higher viral load, alcohol consumption, diabetes mellitus, glutamic oxaloacetic transaminase (GOT), glutamic pyruvic transaminase (GPT), gamma-glutamyl transpeptidase (GGT) bilirubins, and prothrombin time activity (PTA), 
international normalized ratio (INR), albumin, ferritin and transferrin saturation. We also examined co-infections-hepatitis B and HIV infection.

\subsection{Data Analysis}

The results were statistically analyzed using the SPSS 17 software. To analyze the association of selected variables and the presence of cirrhosis, we calculated odds ratio (OR) and their respective confidence intervals (95\% $\mathrm{CI}$ ) as estimates of relative risks, considering the presence of cirrhosis as the dependent variable and the selected variables (those related to disease progression) as independent variables. The variables that were statistically significant in multivariate analysis or p less than or equal to 0.20 were included in the logistic regression model.

\section{Results}

Table 1 shows the sociodemographic and clinical variables. It is evidenced that age (stratified in 15 to 35 years old or older than 35 years old), gender, marital status, occupation (related to the risk of contracting hepatitis C), sexual promiscuity, being a health professional and discontinuation of treatment were not associated with statistical significance at diagnosis of cirrhosis through USG in univariate analysis. The duration of disease has not been studied.

With regard to statistical analysis, initially it was held the data tabulation using descriptive statistics. Then, using inferential statistics, we carried out bivariate analysis using the chi-square test (or Fisher's Exact Test). It was verified the magnitude of association through OR for each of the independent variables with respect to the dependent variable, the 95\% significance level. The variables with ( $p$-value) $p<0.20$ were selected and analyzed with Logistic regression to build the multivariate model, through the Likelihood Ratio Test, absence of multicollinearity, as well as its ability to improve the model using the Hosmer-Lemeshow test. Finally, the variables associated in a statistically significant manner in the final model were Blood Donor and Athlete, adjusted for alcohol consumption (Table 2). The value of Hesmer-Lemeshow test was 0.960 .

\section{Discussion}

As regards the social demographic variables, the athlete with hepatitis $C$ would have less chance to present the diagnosis of cirrhosis (OR 0.179, with $p$ equals to 0.018 ). This could be explained by the fact that the evolution of the disease would present a less aggressive behavior due to the physical activity practiced by athletes. It has been shown that patients with hepatitis $\mathrm{C}$ compared to blood donors would show a decrease in aerobic exercise capacity and consequent overweight, insulin resistance and hepatic steatosis [15].

As for comorbidities, none of the variables was statistically significant. It is known that alcoholism, diabetes, obesity and co-infections by virus B and HIV can accelerate the progression of the disease. However, these associations are challenged by different authors. Recent studies have shown that the development of liver fibrosis in hepatitis C is multifactorial and does not show a linear behavior [16]. White et al. [17] showed that HCV infection is associated with an increased risk of type 2 diabetes, compared to non-infected or infected patients with HBV. Mehta et al. [18] in 2003 showed that HCV is associated with type 2 diabetes in people aged over 40 years. HCV has been considered the major risk factor incident of type 2 diabetes in the post-transplant of liver or kidney, especially in obese and elderly people [19] [20].

Regarding the laboratory variables, bilirubin in the final consultation presented OR 4.773, with $p=0.004$. Is must be highlighted that bilirubin is an important laboratory parameter and is part of all the scores used in Hepatology (Child-Pugh, Meld, Maddrey and Bonacini). In this study, it is noteworthy that the association with the diagnosis of cirrhosis to the ultrasound liver examination refers to the dosage of the final visit. The literature has given little attention the importance of bilirubin as an indicating parameter of cirrhosis in hepatitis C, often highlighting it in the context of cholestatic diseases.

In 2014, Shadid et al. [21] observed higher levels of bilirubin in patients with more severe fibrosis compared with those who were in early stages. Which pathophysiological hypothesis would explain this association due to cirrhosis by $\mathrm{C}$ virus? Would there be the development of a cholangiopathy as a result of the antiviral activity?

Platelets below 150,000 per cubic millimeter, in the initial and final consultation, are in turn important indi- 
Table 1. Sociodemographic and clinical variables, of the case and control subjects, Natal, Rio Grande do Norte, Brazil, 2015.

\begin{tabular}{|c|c|c|c|c|c|}
\hline \multicolumn{6}{|c|}{ Cirrhosis } \\
\hline & Yes & No & OR & CI & $p$ \\
\hline \multicolumn{6}{|c|}{ Age in Years } \\
\hline$>35 \mathrm{a}^{*}$ & 65 & 64 & 1.0 & & \\
\hline 15 to 35 a & 5 & 6 & 1.219 & $0.364-4.196$ & 0.753 \\
\hline \multicolumn{6}{|c|}{ Gender } \\
\hline Male & 53 & 54 & 1.0 & & \\
\hline Female & 17 & 16 & 0.924 & $0.423-2.017$ & 0.842 \\
\hline \multicolumn{6}{|c|}{ Marital status } \\
\hline Not married & 27 & 27 & 1.0 & & \\
\hline Married & 43 & 42 & 0.977 & $0.494-1.932$ & 0.946 \\
\hline \multicolumn{6}{|c|}{ Occupation } \\
\hline Related to risk & 4 & 6 & 1.0 & & \\
\hline No related to risk & 65 & 64 & 0.656 & $0.177-2.436$ & 0.527 \\
\hline \multicolumn{6}{|c|}{ Sexual promiscuity } \\
\hline Yes & 11 & 6 & 1.0 & & \\
\hline No & 57 & 56 & 1.80 & $0.623-5.203$ & 0.272 \\
\hline \multicolumn{6}{|c|}{ Healthcare professional } \\
\hline Yes & 3 & 6 & 1.0 & & \\
\hline No & 67 & 64 & 0.478 & $0.115-1.991$ & 0.301 \\
\hline \multicolumn{6}{|c|}{ Athlete } \\
\hline Yes & 2 & 9 & 1.0 & & \\
\hline No & 67 & 54 & 0.179 & $0.037-0.864$ & 0.018 \\
\hline \multicolumn{6}{|c|}{ Blood donor } \\
\hline Yes & 3 & 9 & 1.0 & & \\
\hline No & 67 & 61 & 0.303 & $0.079-1.173$ & 0.070 \\
\hline \multicolumn{6}{|c|}{ Treatment dropout } \\
\hline Yes & 29 & 32 & 1.0 & & \\
\hline No & 41 & 36 & 0.796 & $0.406-1.560$ & 0.506 \\
\hline \multicolumn{6}{|c|}{ Earlier transfusion } \\
\hline Yes & 22 & 23 & 1.0 & & \\
\hline No & 44 & 44 & 0.957 & $0.466-1.962$ & 0.903 \\
\hline
\end{tabular}

*Age at initial consultation by group: more than 35 years and 15 to 35 years.

cators of cirrhosis when undergoing ultrasound examination. Numerous factors can result in thrombocytopenia, such as infectious diseases, hematological disorders and advanced liver disease. It is known that thrombocytopenia happens as a result of portal hypertension by hypersplenism. It is also known that there may be an au- 
Table 2. Multivariate analysis results of case-control study of patients with chronic hepatitis C diagnosed with cirrhosis through USG in Natal, Rio Grande do Norte, Brazil, 2015.

\begin{tabular}{|c|c|c|c|c|c|c|c|c|}
\hline \multicolumn{9}{|c|}{ Cirrhosis } \\
\hline & \multicolumn{2}{|c|}{ Yes } & \multicolumn{2}{|c|}{ No } & \multirow[b]{2}{*}{$p$} & \multirow[b]{2}{*}{ OR (CI: 95\%) } & \multirow[b]{2}{*}{$p$} & \multirow[b]{2}{*}{$\begin{array}{c}\text { Adjusted OF } \\
\text { (CI: 95\%) }\end{array}$} \\
\hline & $\mathbf{N}$ & $\%$ & $\mathbf{N}$ & $\%$ & & & & \\
\hline \multicolumn{9}{|c|}{ Blood donor } \\
\hline No & 18 & 43.90 & 23 & 56.10 & $0.017^{*}$ & 1.00 & $0.044^{*}$ & 1.00 \\
\hline Yes & 17 & 22.67 & 58 & 77.33 & & $\begin{array}{c}2.67 \\
(1.18-6.06)\end{array}$ & & $\begin{array}{c}0.24 \\
(0.60-0.96)\end{array}$ \\
\hline \multicolumn{9}{|c|}{ Atlhete } \\
\hline No & 51 & 31.10 & 113 & 68.10 & 0.591 & 1.00 & $0.035^{*}$ & 1.00 \\
\hline Yes & 17 & 27.42 & 45 & 72.58 & & $\begin{array}{c}1.19 \\
(0.62-2.28)\end{array}$ & & $\begin{array}{c}0.18 \\
(0.33-0.88)\end{array}$ \\
\hline \multicolumn{9}{|c|}{ Alcohol consumption } \\
\hline No & 15 & 18.52 & 66 & 81.48 & 0.007 & 1.00 & 0.251 & 1.00 \\
\hline Yes & 51 & 35.92 & 91 & 64.08 & & $\begin{array}{c}2.47 \\
(1.28-4.67)\end{array}$ & & $\begin{array}{c}1.62 \\
(0.70-3.73)\end{array}$ \\
\hline
\end{tabular}

Hosmer-Lemeshow test $=0.960 .{ }^{*}$ Blood donor $p=0.044$ with statistic significance adjusted by alcohol consumption. ${ }^{* *}$ Professional Atlhete $p=0.035$ with estatistic significance adjusted by alcohol consumption.

toimmune mechanism. Prevention in the production of thrombopoietin can develop after a long period of necrosis and hepatic fibrosis in patients with advanced chronic hepatitis $\mathrm{C}$, contributing to the decrease of platelet production [22].

In 2006, Sheng-Nan Lu et al. [23] demonstrated that thrombocytopenia had $76.2 \%$ of sensitivity and $87.8 \%$ of specificity for the diagnosis of cirrhosis through USG in patients with chronic hepatitis C virus. Platelet accumulation in the liver with chronic hepatitis can be implied among stellate, and Kupffer cells decrease [24].

The INR is a parameter that characterizes liver function, so as its increase indicates deterioration of functional activity. It can be seen in this study that the INR of the final consultation is clearly an indicator of diagnosis of cirrhosis in undergoing USG examination. In this study, the INR presented odds ratio of 17.875 . Only 2 patients of the sample showed INR $<1.3$. The PTA of the final consultation with cutoff below $70 \%$, was less precise to signal the presence of cirrhosis in USG.

These are important clinical parameters that help the healthcare professional to discern on the diagnosis of cirrhosis, when the biopsy is not available. It should be noted that the accuracy of the INR in this study was higher than the accuracy of PTA. It is possible that this difference is related to sampling quantitative or due to the heterogeneity of laboratory methods in both tests. The literature reports fully the changes in INR and PTA in patients with the diagnosis of cirrhosis [25]-[27].

In the case of the GOT of the final consultation greater than 60 IU (OR 3.267, $p=0.002$ ) it is in accordance with the study of Sheet et al., showing a GOT/GPT ratio greater than 1, where a histopathological worsening and clinical progression to cirrhosis occurs in patients with chronic $C$ virus infection [28].

Among the variables that make up the images examinations block it is important to note that the computed tomography (CT) did not show p value with statistical significance. This result is compatible with that described in the literature and clearly demonstrates that CT is not routinely used for diagnosis of cirrhosis, since the accuracy is not greater than the USG, and it is more costly and exposes the patient to the risks inherent in the method [29].

Still in this set of imaging examinations, it was studied whether the presence of nodules in patients with chronic hepatitis $\mathrm{C}$ would have a positive association with the diagnosis of cirrhosis and no statistical significance was verified. Probably these results could be related to the small number of positive events found [29].

In this study, it was observed that of 67 cirrhotic patients studied, regarding the variable biopsy, 15 had undergone the procedure. The OR was estimated to be 0.402 with $p>0.05$. This result may reflect the technical difficulties in performing these procedures in a population of patients with coagulation disorders, considering 
the risk of bleeding.

On the clinical progression, it was observed that 18 cirrhotic patients underwent antiviral treatment and 3 (16.6\%) of these patients had virus negativity (SVR). This result is in agreement with the study HALT C-Trial Group-that showed a poorer clinical outcome in these patients and low response rates to treatment [30].

The limitations of this study are due to the fact that the selection of cases and controls was made from medical records analysis, though it was obtained retrospectively by systematized calls by completing a standard questionnaire. Another aspect is that it was not possible to perform liver biopsies in all cirrhotic patients, which can signal to operational difficulties to carry out this procedure in this patient population.

This study indicates that clinical and laboratory variables can be grouped into mathematical model for the construction of a clinical score that can support the non-invasive diagnosis of cirrhosis. The importance of this score in the diagnosis of cirrhosis may be proved a posteriori, with the completion of a diagnostic study. This score can be applied in real life, especially in patients with inadequate clinical conditions for performing liver biopsies.

\section{Conclusion}

Cirrhosis condition modifies the clinical course of patients with chronic hepatitis $\mathrm{C}$, making it a disease with a greater chance of complications and painful treatment. This condition, particularly in its compensated forms, has few clinical signs and symptoms and the diagnosis often becomes difficult.

Among all the studied variables, we found that the chances of diagnosis of cirrhosis in patients with chronic hepatitis C would be lower (OR 0.24, $p=0.044$ ) in blood donors through ultrasound, when compared to noncirrhotic HCV positive controls in USG and in non-donors. Also, it was found that the chances of diagnosis of cirrhosis by USG in athletes were estimated to 0.18 with significant $p$ of 0.035 . Being a blood donor and athlete is protective factors that reduce the risk of cirrhosis, independent of alcohol consumption. Moreover, no other clinical or laboratory variable was associated with ultrasound diagnosis of cirrhosis in patients with chronic hepatitis $\mathrm{C}$.

\section{References}

[1] Thein, H.H., Yi, Q., Dore, G.J. and Krahn, M.D. (2008) Estimation of Stage-Specific Fibrosis Progression Rates in Chronic Hepatitis C Virus Infection: A Meta-Analysis and Meta-Regression. Hepatology, 48, 418-431. http://dx.doi.org/10.1002/hep.22375

[2] Tong, M.J., el-Farra, N.S., Reikes, A.R. and Co, R.L. (1995) Clinical Outcomes after Transfusion Associated Hepatitis C. The New England Journal of Medicine, 332, 1463-1466. http://dx.doi.org/10.1056/NEJM199506013322202

[3] Niederau, C., Lange, S., Heintges, T., Erhardt, A., Buschkamp, M., Hürter, D., Nawrocki, M., Kruska, L., Hensel, F., Petry, W. and Häussinger, D. (1998) Prognosis of Chronic Hepatitis C: Results of a Large, Prospective Cohort Study. Hepatology, 28, 1687-1695. http://dx.doi.org/10.1002/hep.510280632

[4] D’Amico, G., Garcia-Tsao, G. and Pagliaro, L. (2006) Natural History and Prognostic Indicators of Survival in Cirrhosis: A Systematic Review of 118 Studies. Journal of Hepatology, 44, 217-231. http://dx.doi.org/10.1016/j.jhep.2005.10.013

[5] Morgan, R.L., Baack, B., Smith, B.D., Yartel, A., Pitasi, M. and Falck-Ytter, Y. (2013) Eradication of Hepatitis C Virus Infection and the Development of Hepatocellular Carcinoma: A Meta-Analysis of Observational Studies. Annals of Internal Medicine, 158, 329-337. http://dx.doi.org/10.7326/0003-4819-158-5-201303050-00005

[6] Morgan, T.R., Ghany, M.G., Kim, H.Y., Snow, K.K., Shiffman, M.L., De Santo, J.L., et al. (2010) Outcome of Sustained Virological Responders with Histologically Advanced Chronic Hepatitis C. Hepatology, 52, 833-844. http://dx.doi.org/10.1002/hep.23744

[7] Poynard, T., Bedossa, P. and Opolon, P. (1997) Natural History of Liver Fibrosis Progression in Patients with Chronic Hepatitis C. The OBSVIRC, METAVIR, CLINIVIR, and DOSVIRC Groups. The Lancet, 349, 825-832.

[8] Poynard, T., Munteanu, M., Imbert-Bismut, F., Charlotte, F., Thabut, D., Le Calvez, S., Messous, D., Thibault, V., Benhamou, Y., Moussalli, J. and Ratziu, V. (2004) Prospective Analysis of Discordant Results between Biochemical Markers and Biopsy in Patients with Chronic Hepatitis C. Clinical Chemistry, 50, 1344-1355. http://dx.doi.org/10.1373/clinchem.2004.032227

[9] Bedossa, P., Dargère, D. and Paradis, V. (2003) Sampling Variability of Liver Fibrosis in Chronic Hepatitis C. Hepatology, 38, 1449-1457. http://dx.doi.org/10.1016/j.hep.2003.09.022

[10] Piccinino, F., Sagnelli, E., Pasquale, G. and Giusti, G. (1986) Complications Following Percutaneous Liver Biopsy. A 
Multicentre Retrospective Study on 68,276 Biopsies. Journal of Hepatology, 2, 165-173.

[11] Perrault, J., McGill, D.B., Ott, B.J. and Taylor, W.F. (1978) Liver Biopsy: Complications in 1000 Inpatients and Outpatients. Gastroenterology, 74, 103-106.

[12] Imbert-Bismut, F., Ratziu, V., Pieroni, L., Charlotte, F., Benhamou, Y., Poynard, T. and Multivirc Group (2001) Biochemical Markers of Liver Fibrosis in Patients with Hepatitis C Virus Infection: A Prospective Study. The Lancet, 357, 1069-1075.

[13] Fontana, R.J., Goodman, Z.D., Dienstag, J.L., Bonkovsky, H.L., Naishadham, D., Sterling, R.K., Su, G.L., Ghosh, M., Wright, E.C. and HALT-C Trial Group (2008) Relationship of Serum Fibrosis Markers with Liver Fibrosis Stage and Collagen Content in Patients with Advanced Chronic Hepatitis C. Hepatology, 47, 789-798. http://dx.doi.org/10.1002/hep.22099

[14] Sharma, S., Khalili, K. and Nguyen, G.C. (2014) Non-Invasive Diagnosis of Advanced Fibrosis and Cirrhosis. World Journal of Gastroenterology, 20, 16820-16830. http://dx.doi.org/10.3748/wjg.v20.i45.16820

[15] Yonossi, Z., Lynn, G., Fang, Y., Srishord, M., Winter, P., Kallman, J. and Moon, J. (2012) Disparities in Activity Level and Mutrition between Patients with Chronic Hepatitic C and Blood Donors. The American of Physical Medicine and Rehabilitation, 4, 436-441.

[16] Dusheiko, G. and Westbrook, R.H. (2014) Natural History of Hepatitis C. Journal of Hepatology, 61, 558-568.

[17] White, D.L., Ratziu, V. and El-Serag, H.B. (2008) Hepatitis C Infection and Risk of Diabetes: A Systematic Review and Meta-Analysis. Journal of Hepatology, 49, 831-844. http://dx.doi.org/10.1016/j.jhep.2008.08.006

[18] Mehta, S.H., Brancati, F.L., Strathdee, A.S., Pankow, J.S., Netski, D., Coresh, J., Szklo, M. and Thomas, D.L. (2003) Hepatitis C Virus Infection and Incident Type 2 Diabetes. Hepatology, 38, 50-56. http://dx.doi.org/10.1053/jhep.2003.50291

[19] Delgado-Borrego, A., Liu, Y.S., Jordan, S.H., Agrawat, S., Zhang, H., Christofi, M., et al. (2008) Prospective Study of Liver Transplant Recipients with HCV Infection: Evidence for a Causal Relationship between HCV and Insulin Resistance. Liver Transplantation, 14, 183-201. http://dx.doi.org/10.1002/lt.21267

[20] Fabrizi, F., Messa, P., Martin, P. and Takkouche, B. (2008) Hepatitis C Virus Infection and Post-Transplant Diabetes Mellitus among Renal Transplant Patients: A Meta-Analysis. International Journal of Artificial Organs, 31, 675-682.

[21] Shahid, M., Idrees, M., Nasir, B., Raja, A.J., Raza, S.M., Amin, I., Rasul, A. and Tayyab, G.U. (2014) Correlation of Biochemical Markers and HCV RNA Titers with Fibrosis Stages and Grades in Chronic HCV-3a Patients. European Journal of Gastroenterology \& Hepatology, 26, 788-794. http://dx.doi.org/10.1097/MEG.0000000000000109

[22] Shah, N.L., Northup, P.G. and Caldwell, S.H. (2015) Coagulation Abnormalities in Patients with Liver Disease. UPTODATE 18.0, February 2015.

[23] Lu, S.N., Wang, J.H., Liu, S.L., Hung, C.H., Chen, C.H., Tung, H.D., Chen, T.M., Huang, W.S., Lee, C.M., Chen, C.C. and Changchien, C.S. (2006) Thrombocytopenia as a Surrogate for Cirrhosis and a Marker for the Identification of Patients at High-Risk for Hepatocellular Carcinoma. Cancer, 107, 2212-2222. http://dx.doi.org/10.1002/cncr.22242

[24] Kondo, R., Yano, H., Nakashima, O., Tanikawa, K., Nomura, Y. and Kage, M. (2013) Accumulation of Platelets in the Liver May Be an Important Contributory Factor to Thrombocytopenia and Liver Fibrosis in Chronic Hepatitis C. Journal of Gastroenterology, 48, 526-534. http://dx.doi.org/10.1007/s00535-012-0656-2

[25] Lisman, T., Liebeek, F.W.G. and Groot, P.G. (2002) Haemostatic Abnormalities in Patients with Liver Disease. Journal of Hepatology, 37, 280-287. http://dx.doi.org/10.1016/S0168-8278(02)00199-X

[26] Caldewell, S.H., Hoffman, M., Lisman, T., Marik, B.G., Northup, P.G., Reddy, K.R., et al. (2006) Coagulation Disorders and Hemostasis in Loiver Disease: Pathophysiology and Critical Assessment of Current Management. Hepatology, 44, 1039-1046. http://dx.doi.org/10.1002/hep.21303

[27] Tripoli, A., Caldwell, S.H., Hoffman, M., Trotter, J.F. and Sanyal, A.J. (2007) Review Article: The Prothrombin Time Test as a Measure of Bleeding Risk and Prognosis in Liver Disease. Alimentary Pharmacology \& Therapeutics, 26, 1418.

[28] Shet, S.G., Flamm, S.L., Gordon, F.D. and Choopra, S. (1998) AST/ALT Ratio Predicts Cirrhosis in Patients with Chronic Hepatitis C Virus Infection. American Journal of Gastroenterology, 93, 44-48. http://dx.doi.org/10.1111/j.1572-0241.1998.044_c.X

[29] Golbberg, E. and Chopra, S. (2015) Cirrhosis in Adults: Etiologies, Clinical Manifestations, and Diagnosis. UPTODATE, 18.0, February 2015.

[30] Ghany, M.G., Lok, A.S., Everhart, J.E., Everson, G.T., Lee, W.M., Curto, T.M., Wright, E.C., Stoddard, A.M., Steling, R.K., Di Bisceglie, A.M., Bonkovsky, H.L., Morishima, C., Morgan, T.R. and Dientag, J.L., HALT-C Trial Group (2010) Predicting Clinical and Histologic Outcomes Based on Standard Laboratory Tests in Advanced Chronic Hepatitis C. Gastroenterology, 138, 136-146. http://dx.doi.org/10.1053/j.gastro.2009.09.007 